\title{
Extracellular vesicles derived from gut microbiota in inflammatory bowel disease and colorectal cancer
}

\author{
Giusi Albertia\#, Margherita Mazzolaa", Carola Gagliardob , Alessandro Pitruzzellaa, Alberto Fucarinia,

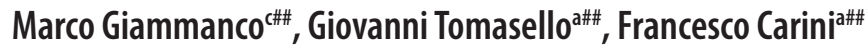

The human gut microbiome encompasses inter alia, the myriad bacterial species that create the optimal host-microorganism balance essential for normal metabolic and immune function. Various lines of evidence suggest that dysregulation of the microbiota-host interaction is linked to pathologies such as inflammatory bowel disease (IBD) and colorectal cancer (CRC). Extracellular vesicles (EVs), found in virtually all body fluids and produced by both eukaryotic cells and bacteria are involved in cell-cell communication and crosstalk mechanisms, such as the immune response, barrier function and intestinal flora. This review highlights advancements in knowledge of the functional role that EVs may have in IBD and CRC, and discusses the possible use of EVs derived from intestinal microbiota in therapeutic strategies for treating these conditions.

Key words: extracellular vesicles, gut microbiota, inflammatory bowel disease, colorectal cancer

Received: February 25, 2021; Revised: May 10, 2021; Accepted: June 16, 2021; Available online: July 2, 2021

https://doi.org/10.5507/bp.2021.042

(c) 2021 The Authors; https://creativecommons.org/licenses/by/4.0/

aInstitute of Human Anatomy and Histology, Department of Biomedicine, Neurosciences and Advanced Diagnostics, (BIND), University Hospital Policlinico Paolo Giaccone of Palermo, Palermo, Italy

${ }^{b}$ Department of Health Promotion, Mother and Child Care, Internal Medicine and Medical Specialties, Palermo, Italy

'Department of Surgery, Oncologicical and Stomatological Sciences (Di.Chir.On.S), University Hospital Policlinico Paolo Giaccone of

Palermo, Palermo, Italy

"These authors contributed equally

\#These authors contributed equally

Corresponding author: Margherita Mazzola, e-mail: margheritamazzola@hotmail.it

\section{INTRODUCTION}

In the last few years, the intestinal microbiota has become a focus of prolific research for its pivotal role in human health and disease. It is understood that our gut hosts more than 1000 bacterial species, defined as our hidden metabolic "organ" for its immense impact on human wellbeing. The gut microbiota consists of a multispecies microbial community composed of bacteria, viruses, yeast, fungi, and others capable of establishing symbiosis with the host organism ${ }^{1,2}$. In particular, about $90 \%$ of the total microbiome of the mammalian gut is represented by two main commensal bacteria groups: Firmicutes (gram-positive bacteria) and Bacteroidetes (gram-negative bacteria) ( ref. $^{3}$ ). The microbial community has been shown to be implicated in several processes ranging from energy harvest and storage ${ }^{4}$, to normal intestinal development through several mechanism, among which the processes that lead to the formation of short chain fatty acids (SCFA), such as butyrate involved in intestinal homeostasis ${ }^{5}$. Furthermore, some commensal bacteria (e.g. Bacteroides fragilis) participate at the synthesis of vitamins, such as B vitamins, with an important role in the maintenance of immune homeostasis ${ }^{6}$. It has been demonstrated that commensal bacteria shape oth innate and adaptive immunity ${ }^{7}$. In particular, the host- commensal microbiota communication is triggered from soluble mediators and extracellular vesicles (EVs) that can diffuse through the mucin layer, influencing the maturation and development of the digestive and immune system $^{8,9}$. From a physical point of view, this is guaranteed by the separation of commensal bacteria from the epithelial layer by of a highly compact mucus layer which prevents the entry of bacteria ${ }^{10}$. A mechanism that favors the host-commensal bacteria interaction involves EVs derived from bacteria that carry molecules with signaling properties, in combination with other mechanisms. The EVs released by commensal bacteria can be taken up by eukaryotic host cells modulating changes, as well as alteration of the gene expression ${ }^{11}$. For example, EVs derived from B. fragilis are enriched in immunomodulatory molecules (i.g. capsular lipolysaccharide A, PSA) which induces protection against colitis by an autophagy pathway that involves genes associated with IBD, Nucleotide Binding Oligomerization Domain Containing 2 (NOD2) and Autophagy related 16 like 1 (ATG16L1) (ref. ${ }^{12}$ ). Likewise, bacterial EVs when absorbed by macrophages can induce a massive release of pro-inflammatory cytokines, such as Tumor Necrosis Factor alpha (TNF- $\alpha$ ) and interleukin -6 (IL-6). By contrast, EVs released from the bacterium Campylobacter jejuni possess cytotoxic 
activity able to induce an immune response in the host ${ }^{13}$, and EVs-derived from Bacteroides thetaiotaomicron have the ability to cross the intestinal mucosal barrier reaching the intestinal cells and initiating a localized inflammation process $^{14}$. Despite the important functions of bacterial EVs, to date, the mechanism of biognesis remains poorly known vis a vis that of eukaryotic cells. Consequently, it is plausible to think of an involvement of EVs derived from intestinal microbiota in the systemic inflammatory responses with an important role in the development of colorectal cancer (CRC). Here, we review the different mechanisms of inter-cellular communication between bacterial and host cells in CRC and their potential effect on inflammatory bowel disease (IBD) (ref. ${ }^{15-19}$ ).

\section{EXTRACELLULAR VESICLES DERIVED FROM GUT BACTERIAL}

Currently, the ubiquity of EVs in all the kingdoms of life, iks well-known, underlining their high evolutionary importance ${ }^{20}$. All gram-negative and some gram-positive bacteria constitutively generate EVs from the outer membrane and accordingly, namely outer membrane vesicles

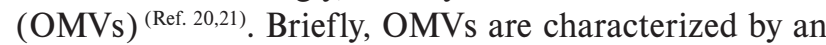
external lipopolysaccharide sheet and an internal phospholipid sheet, enriched in membrane and surface proteins given their origin. Unlike mammalian EVs, OMVs are particularly enriched in cell wall components, peptidoglycans, lipopolysaccharides (LPS), phospholipids, as well as soluble proteins, and others ${ }^{22}$. Although OMVs are passively produced under natural conditions, they may be released in greater numbers in response to stress, either via explosive cell lysis or actively ${ }^{23}$. However, the exact mechanism that results in outer membrane budding remains unknown making it challenging to unravel the basic mechanisms of vesicle transport. In consideration of this, several models for OMV biogenesis are currently being discussed, as well as autolysin ${ }^{24}$, DNA fragments ${ }^{25,26}$, biofilm formation ${ }^{27,28}$, toxin delivery ${ }^{29}$, antibiotic resistance ${ }^{30}$, and the transfer of nucleic acids ${ }^{31-33}$. Generally, they have ranges from less than $100 \mathrm{~nm}$ to a few hundred nanometers, and are considered to be distinct communication system between cells and cooperation including multicellular development, quorum sensing, and virulence factors ${ }^{34-36}$. Also, OMVs surrounding bacteria can protect from viral attack for example by absorbing viruses ${ }^{37}$, or to excrete misfolded proteins following to stress response ${ }^{38}$. In addition to this knowledge, it should be added that, OMVs have the immunogenic capacity to carry a wide spectrum of endogenous antigens, and the natural self-adjuvanticity exerted by toll-like receptor (TLR) agonists, such as LPS $\left(\right.$ ref. $\left.{ }^{39}\right)$. Considering this, we will briefly discuss the process of Gram negative and Gram positive EVs biogenesis.

\section{Gram-negative bacteria}

The first identified of the presence of OMVs in gramnegative bacteria dates back to 1960 s by observing bacterial structure by electron microscopy ${ }^{40}$. Gram-negative bacteria have two main pathways for vesicle biogenesis.
Brefly, the first pathway of formation involves the blebbing of the outer membrane of the bacterial envelope with generation the OMV, while the second involves the explosive cell lysis with formation of vesicles of the outer-inner membrane (OIMV) and explosive vesicles of the outer membrane (EOMV) (ref. $\left.{ }^{41}\right)$. EVs produced by Gram-negative bacteria secreted EVs with sizes ranging from 10 to $400 \mathrm{~nm}$ by breaking the connection directly in specific areas ${ }^{42-43}$. This process can lead to the incorporation of peptidoglycan and fragment of OM-peptidoglycan bridging proteins in the $\mathrm{OMV}^{44}$, since they have a cell wall consisting of a thin layer of peptidoglycan in the periplasmic space between two double layers of membrane, the inner (or cytoplasmic) membrane and the outer one ${ }^{41}$. The outer membrane contains LPS and many membranebound proteins and channels, such as porins, that intervene in the non-vesicle mediated transport ${ }^{41}$. Given this architecture, the outer membrane of Gram-negative is known to engage Toll-like receptor 4 (TLR4) (Ref.45) . Gramnegative EVs carry bacterial components including proteins, peptiglycan, LPS, O-antigen, nucleic acid, enzymes and other moleculs ${ }^{44-49}$, and probably the different biogenesis route is responsible of a different composition. Gram-negative EVs are involved in intra-and-intercellular communication and mediating a plethora of biological processes. Accordingly, they can also deliver their cargoes (e.g toxins and virulence factor) to prokaryotic kingdoms and eukaryotic cells regulating many processes including host-pathogen interaction, regulation of the host immune response, and others ${ }^{50,51}$. Of note, intraluminal DNA from gram-negative EVs has been observed to be enriched in specific regions of the bacterial chromosome and to be involved in virulence, stress response, antibiotic resistance and metabolism ${ }^{52}$.

\section{Gram-positive bacteria}

In the 1990s, it was discovered that Gram-positive bacteria (Bacillus subtilis and Bacillus cereus) were also able to release membrane vesicles ${ }^{53}$. Unlike gram-negative bacteria, gram-positive bacteria lack an outer membrane and present a thick peptidoglycan layer composing their cell walls ${ }^{41}$. To date, the specific mechanisms behind the release of EVs in Gram-positive bacteria are not fully understood, but support for the hypothesis that describes the origin of the EVs from the cytoplasmic membrane named as cytoplasmic membrane vesicles (CMVs) (ref. ${ }^{41,54}$ ). Consequently, EVs-secreted from Gram-positive bacteria do not show the characteristic toxicity of the LPS, the main component of the bilayered lipids of OMVs, but are particularly enriched in lipoteichoic acid (LTA) that might engage the Toll-like receptor 2 (TLR2) (ref. ${ }^{55}$ ). This difference in composition makes it possible to distinguish EVs from gram positive bacteria ${ }^{56,57}$. EVs secreted by gram-positive bacteria intervene in the pathogen-host interaction and in the regulation of inflammatory processes by their molecules cargo ${ }^{58}$. For example, it has been demonstrated that the pneumococcal surface protein A (PspA), expressed by all strains of Streptococcus pneumoniae, when introducted into a gram-negative Salmonella enterica strain and, in turn, released into EVs, is capable 
of conferring immunity to mice treated with the latter ${ }^{59}$. For their safety features and others, EVs released from gram-positive bacteria are currently under investigation as an antigen adjuvant for vaccine candidate ${ }^{60}$.

\section{POTENTIAL OF BACTERIAL EVS IN IBD AND CRC}

EVs play an important role in carcinogenesis, particularly in cancer progression and growth. They interacting with a variety of cells within the tumour microenvironment favoring cell proliferation, angiogenesis (e.g. thourgh the induction of vascular endothelial growth factor (VEGF) expression and the autocrine activation of its receptor), promoting metastases, and transmitting chemoresistence abilities to nearby cells. Also, EVs might play a role in the induction of immune tolerance in cancer cells, for example, by modulating the activity of T cells ${ }^{61,62}$. EVs have been studied in many pathological and non- pathological conditions, including CRC and IBD. IBD forms a group that encompasses chronic autoimmune diseases that affect the gastrointestinal tract. They are emerging as an inflammatory component coupled with immune dysregulation responsible for the damages to the gastrointestinal $\operatorname{tract}^{63}$. Regardless of source of the EVs, they can be released by immune cells (i.e. macrpghages, monocytes and dendritic cells), intestinal epithelial cells (IECs), stem cells, tumor cells, and others. Besides, EVs from some nutritional sources have attracted interest due to the fact that they are ingested daily and therefore are generally considered safe. For example, breast milk contains a diversity of biologically active components like EVs that, together with the microbiota, assist in mucosal tissue, immune system and microbiome development and maintenance ${ }^{64}$. This highlights that EVs do not just regulate gut microbiome communities, but actively participate in the disharmony between bacteria and their hosts. Here the focus on associations that are the focus of greatest attention, that is, the possibility of a link between the gut microbiota and a chronic gastrointestinal disease, i.e IBD, as well as the onset of CRC (Table1).

\section{IBD}

IBD is the consequence of a dysregulated mucosal immune system and has been extensively studied. IBD patients have a higher concentration of EVs than the healthy subject, thus representing potential biomarkers. The expression of such biomarkers within the serum and tissues of IBD patients would indicate the onset of a molecular and genetic imbalance originating probably from pro-inflammatory conditions. EVs contain molecules from their parental cells, including proteins, lipids, and miRNAs, through which they can intervene in different processes, including promoting pro-inflammatory conditions $^{71}$. EVs derived by intestinal luminal aspirate from IBD subjects contain markedly higher mRNA and protein levels of IL-6, interleukin - 8 (IL-8), and TNF- $\alpha$ than those of healthy controls. In detail, EVs are absorbed by colonic epithelial cells, resulting in an increase in the level of IL-8 expression and subsequent induction of macrophage migration by epithelial cells ${ }^{72}$. IECs are among the first to perceive luminal stimuli related to the entry of food, pathogens and more capable of triggering the encounter with IBD. It has been reported that EVs released from IECs play important roles in immune tolerance, and can function critically in immune responses in the pathogenesis of $\mathrm{IBD}^{73}$. EVs secreted by the IECs interact preferentially with dendritic cells (DCs), thus intervening in the presentation of exogenous antigens through their major histocompatibility complex of class II (MHC-II) $\left(\right.$ ref. $\left.^{73}\right)$. In this manner, these EVs link local immune cells and luminal antigens in a powerful way through mediated transfer of luminal antigenic information and to facilitate immune surveillance on mucosal surfaces ${ }^{73}$. EVs released by IECs are able to limit expansion of CD4+ T cells, and of T helper 1 (Th1) and T helper 2 (Th2). In turn, IECs intervene in the interaction between gut microbiome and immune cells ${ }^{74}$. EVs luminal play important role in the IECs-microbiome-immune system interaction to maintain mucosal homeostasis ${ }^{74}$. Other studies have demonstrated that the involvement of EVs in the activation of macrophages having a key role in the pathogenesis of IBD, because they are involved in the maintenance of homeostasis and regulation of the intestine ${ }^{75}$. In the IBD microenvironment, EVs inducing Treg, regulatory DCs and M2 phenotype macrophages, resulting in immunosuppressive action on the host immune system. Major histocompatibility complex of class I (MHC-I) on the surface of EVs can mediate apoptosis of CD8+T cells through regulating the activity of natural killer cells and DCs mediating inflammation tolerance ${ }^{76}$. Besides, in the pathogenesis of IBD, have been investigated he heat shock protein (Hsp), as Hsp70 particularly enriched in EVs (ref. ${ }^{77}$ ). Exosomal HSP70 interact with gram-negative

Table 1. Correlation between gut microbiota diversity and pathological condition.

\begin{tabular}{|c|c|c|c|}
\hline Pathological condition & $\begin{array}{l}\text { Increase of some microbes in rela- } \\
\text { tion to the disease }\end{array}$ & $\begin{array}{l}\text { Decrease of some microbes in relation to } \\
\text { the disease }\end{array}$ & Ref. \\
\hline IBD (incl. CD and UC) & $\begin{array}{l}\text { Gamma-proteobacteria, } \\
\text { Enterobacteraceae, } \\
\text { Escherichia coli, } \\
\text { Clostridium spp. }\end{array}$ & $\begin{array}{l}\text { Firmicutes } \\
\text { Bacteroidetes } \\
\text { Lachnospiracheae } \\
\text { Clostridium leptum } \\
\text { Coccoides group }\end{array}$ & $65-67$ \\
\hline $\mathrm{CRC}$ & $\begin{array}{l}\text { Fusobacterium spp. } \\
\text { E. coli }\end{array}$ & Not dectable & $68-70$ \\
\hline
\end{tabular}


bacteria receptors, i.e. TLR4 and gram-positive bacteria receptors (TLR2), to stimulate proinflammatory responses and, also, exosomal heat shock protein 72 (HSP72) in the functions of IECs $\left(\right.$ ref. $\left.^{78}\right)$. The upregulation of heat shock protein 60 (Hsp60) in cells typical of inflammation of the lamina propria (eg CD68 cells), following alterations in the homeostasis of the MuMi layer, suggests that this chaperonin may be involved in the activation of the immune system and therefore in evolution of the inflammatory process ${ }^{79}$. Accordingly, EVs might play a pro-inflammatory role during active IBD, by inducing, maintaining and regulating the required functions of intestinal tissues. These modulatory properties exhibited by EVs make them ideal candidates for the treatment and prevention of IBD relapses ${ }^{79}$. Currently, hyperactivation of pro-inflammatory pathways is blocked i.e by inhibition of tumor necrosis factor TNF- $\alpha$, gut-homing $\alpha 4 \beta 7$ integrin, interleukin 12 (IL-12) (ref. ${ }^{80}$ ), given their capacity to induce serious negative effects, including infections and malignancies ${ }^{81}$. EVs-derived from enteropathogenic bacteria induce the secretion of intestinal mucosa-derived EVs carrying an elevated level of $\mathrm{C}-\mathrm{C}$ motif chemokine 20 (CCL20) and prostaglandin E2 (PGE2) causing inflammation $^{82}$. Oxidative antimicrobial activity induces an increase in proteins in EVs at the interface between the intestinal mucosa and the intestinal lumen in IBD patients compared to control subjects ${ }^{83}$. Intestinal microbiota plays a major role in the development of IBD (ref. ${ }^{84}$ ). In Figure 1 , we show the involvement of gut microbiota in maintaining intestinal homeostasis following activation of inflammatory pathways underlies IBD pathogenesis ${ }^{85}$.

Fig. 1. Schematic illustration of involvement of gut microbiota in maintaining intestinal homeostasis following to activation of inflammatory pathways underlies
IBD pathogenesis. Both macrophages and DCs actively promote the transition from inflammation to the return to homeostasis after immune system activation, by internalizing EVs which mediates an immunomodulatory response through Toll-like receptors (TLR2 and TLR4) signaling. Once activated, the DCs promote the release of anti-inflammatory cytokines, such as IL-4, IL-10, and IL22, and down regulating of pro-inflammatory cytokines. Also, EVs interacting with intestinal epithelial cells favoring the expression of tight junction proteins and, in turn, modulating cytokine secretion, with consequent reinforcementof the intestinal barrier. Both mechanisms contribute, modulation of the immune response and improvement of the gut barrier ${ }^{85}$.

Microbial dysbiosis is an important contributing factor to oncogenesis and tumor progression including colorectal cancer, which may also adversely affect treatment response to chemotherapy and immunotherapy ${ }^{86}$.

\section{CRC}

Colorectal cancer (CRC) is one of the most common malignant tumors, ranking in the top 3 causes of cancerrelated death worldwide. High-throughput microbiome sequencing has shown that patients with CRC have reduced bacterial diversity and richness compared with those of healthy individuals ${ }^{87}$. However, conflicting results make the precise community dynamics between the gut microbiota and CRC unclear. It has been shown that one of the most consistent bacterial groups associated with CRC carcinogenesis is Bacteroides spp., in particular Bacteroides fragilis implicated in an increase in inflammation $^{88,89}$. Furthermore, the intestinal microbiota CRC

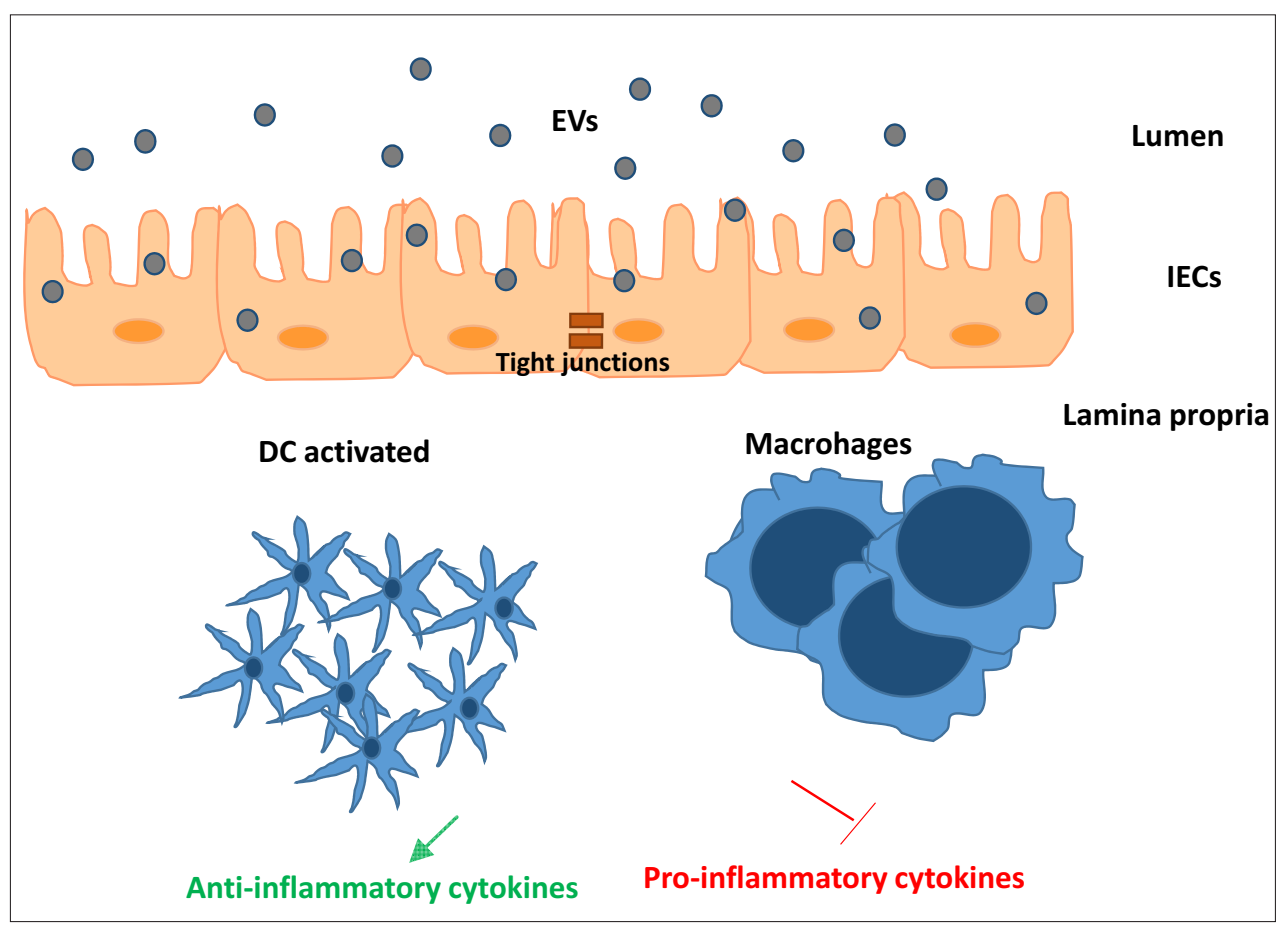

Fig. 1. Gut microbiota and intestinal homeostasis in pathogenesis of IBD. 
is characterized by a lower presence of lactic bacteria, a greater presence of Fusobacterium and altered levels of Bacteroides/Prevotella ${ }^{90}$. Jung and coworkers demonstrated the correlation between microbial changes and metabolic alterations within EV samples from patients with CRC. There was a strong association between the abundance of gut flora (Firmicutes and Proteobacteria) and relevant candidate metabolites (predominantly amino acids) (ref..$^{90}$ ). This suggests that altered composition of macronutrient-fermenting and degrading bacteria in CRC might result in the accumulation of amino acids and the depletion of energy sources. Moreover, our findings indicate that EVs secreted by gut microbes carry a dynamic range of metabolic information reflecting the host's nutritional state, metabolism, and immune responses in the presence of disease ${ }^{91}$. The mechanism by which bacteria affect carcinogenesis and tumor progression are different, for example they could act as tumor promoting entities by invoking tolerogenic immune reprogramming of the micro environment (TME). It has been proposed that EVs secreted by the gut microbiota could drive suppressive cellular differentiation in a TLR-dependent manner, to indirectly elicit T-lymphocyte anergy ${ }^{92}$. Also, it has been observed that EVs infected by toxins can be released by some intestinal bacteria promoting the development of CRC by exacerbating an inflammatory condition. For example, fragilisin toxin secreted into EVs by Bacteriodes fragilis is able to promote tumor growth of the colon mediating both splitting of E-cadherin ${ }^{86}$ and production of IL-8 $\left(\right.$ ref. $\left.^{79}\right)$. CRC patients have an increase in Bacteroidetes which can control inflammation by regulating the differentiation of Tregs. Capsular polysaccharide A released by $\mathrm{B}$. fragilis has immunoregulatory properties by which it mediates the conversion of CD $4+\mathrm{T}$ cells to Foxp 3 + Treg via TLR2-mediated signaling. These cells have a greater suppressive capacity through increased production of the anti-inflammatory cytokine interleukine 10 (IL-10) (ref. $\left.{ }^{93}\right)$. Popēna et all have reported that primary CRCderived EVs modulate the immunophenotype and secretory profile of monocytes and inactive macrophages towards M1 type of response whereas metastatic CRC-derived EVs induce a mixed M1 and M2 cytokine response in inactive macrophages in the THP-1 monocyte differentiation model. Furthermore, although CRC EVs decrease HLA-DR expression in M1 and M2 polarized macrophages, their effect on the secretory profile of these cells is negligible ${ }^{94}$. Together these studies provide evidence to support the notion that there may be two-way IV-mediated communication between bacteria and human host cells. However, to date, there is no mechanistic study investigating how bacterial EVs can impact oncogenesis and tumor progression, and their role is likely to be context-dependent.

\section{CONCLUSION}

Various lines of evidence suggest that dysregulation of microbiota-host interaction is linked to various pathologies, such as IBD and CRC. An ever-growing number of studies have highlighted the key role of EVs as a source of diagnostic and prognostic markers or as promising pharmaceutical vehicles. Scientific interest in EVs has been stimulated due to their key role in cell-cell and cellorganism communication. Many studies have shown that circulating EVs increase in patients with gastrointestinal tumors, compared to patients with inflammatory gastrointestinal diseases such as IBD $^{95-97}$. Nevertheless, it is likely that the amount of circulating EVs is high in the active phase of inflammatory diseases in comparison to healthy people $^{98}$.A higher number of EVs was found in IBD patients in remission than in healthy donors supporting the inflammatory cell recruitment hypothesis ${ }^{99}$. Recently, one study has reported that intestinal luminal fluid is enriched in proinflammatory EVs of various origins (e.g secreted by cells that structure the intestinal wall or vesicles of the bacterial outer membrane) carrying markers IL8, IL6, IL10 and TNF (ref. ${ }^{100,101}$ ). Apropos CRC, a number of publications describe the microRNA profile in supernatants of epithelial cell line biomarker cultures as good biomarker candidates for $\mathrm{CRC}^{102}$. However, there is always a tendency to consider the functions of EVs on inflammatory gastrointestinal diseases and gastrointestinal tumors from the point where EVs originate only from eukaryotic cells, neglecting EVs originating from the human microbiota. This suggests a possible therapeutic role of AmEV in the treatment of chronic intestinal inflammation. Consequently, the administration of EVs derived from specific bacterial strains can modulate the immune signaling pathways and other related processes. Finally, the use of EVs could allow the construction of a network of ecological units organized within the intestinal microbiota capable of bringing about improvements in a number of pathological conditions.

\section{Search strategy and selection criteria}

Our aim was to offer an overview of EVs with particular attention to their possible therapeutic role. Expanding therapeutic perspectives towards IBD and CRC could guarantee better patient outcomes in terms of disease remission and life expectancy. Scientific articles were searched using the PubMed adatabases. All searches were up to date as of 2020. The search terms used included "extracellular vesicles", "gut microbiota", "inflammatory bowel disease", "colorectal cancer".

Author contributions: GA, MM: drafting, composition and correction of the article; $\mathrm{CG}, \mathrm{AF}, \mathrm{AP}$ : litearature research; MG, GT, FC: coordination, correction and evaluation.

Conflict of Interest statement: The authors state that there are no conflicts of interest regarding the publication of this article.

\section{REFERENCES}

1. Ley RE, Peterson DA, Gordon Jl. Ecological and evolutionary forces shaping microbial diversity in the human intestine. Cell 2006; 124(4):837-48.

2. Ley RE, Hamady M, Lozupone C, Turnbaugh PJ, Ramey RR, Bircher JS, Schlegel ML, Tucker TA, Schrenzel MD, Knight R, Gordon Jl. Evolution of mammals and their gut microbes. Science 2008; 320(5883):164751. 
3. Rinninella $E$, Raoul $P$, Cintoni $M$, Franceschi $F$, Miggiano GAD, Gasbarrini A, Mele MC. What is the Healthy Gut Microbiota Composition? A Changing Ecosystem across Age, Environment, Diet, and Diseases. Microorganisms 2019;10:7.

4. Clemente JC, Ursell LK, Parfrey LW, Knight R. The impact of the gut microbiota on human health: an integrative view. Cell 2012;148(6):1258-70.

5. Heerdt BG, Houston MA, Augenlicht LH. Short-chain fatty acid-initiated cell cycle arrest and apoptosis of colonic epithelial cells is linked to mitochondrial function. Cell Growth Differ 1997;8(5):523-32.

6. Hosomi K, Kunisawa J. The Specific Roles of Vitamins in the Regulation of Immunosurveillance and Maintenance of Immunologic Homeostasis in the Gut. Immune Netw 2017;17(1):1319.

7. Smith K, McCoy KD, Macpherson AJ. Use of axenic animals in studying the adaptation of mammals to their commensal intestinal microbiota. Semin Immunol 2007;19(2):59-69.

8. Vaishnava S, Yamamoto M, Severson KM, Ruhn KA, Yu X, Koren O, Ley R, Wakeland EK, Hooper LV. The antibacterial lectin Reglllgamma promotes the spatial segregation of microbiota and host in the intestine. Science 2011;334(6053):255-8.

9. Lazar V, Ditu LM, Pircalabioru GG, Gheorghe I, Curutiu C, Holban AM, Picu A, Petcu L, Chifiriuc MC. Aspects of Gut Microbiota and Immune System Interactions in Infectious Diseases, Immunopathology, and Cancer. Front Immunol 2018; 9:1830.

10. Macia L, Nanan R, Hosseini-Beheshti E, Grau GE. Host- and Microbiota-Derived Extracellular Vesicles, Immune Function, and Disease Development. Int J Mol Sci 2019;21(1):107.

11. Ahmadi Badi S, Moshiri A, Fateh A, Rahimi Jamnani F, Sarshar M, Vaziri F, Siadat SD. Microbiota-Derived Extracellular Vesicles as New Systemic Regulators. Front Microbiol 2017;8:1610.

12. Barteneva NS, Baiken Y, Fasler-Kan E, Alibek K, Wang S, Maltsev N, Ponomarev ED, Sautbayeva Z, Kauanova S, Moore A, Beglinger $C$, Vorobjev IA. Extracellular vesicles in gastrointestinal cancer in conjunction with microbiota: On the border of Kingdoms. Biochim Biophys Acta 2017;1868(2):372-93.

13. Elmi A, Watson E, Sandu P, Gundogdu O, Mills DC, Inglis NF, Manson E, Imrie L, Bajaj-Elliott M, Wren BW, Smith DG, Dorrell N. Campylobacter jejuni outer membrane vesicles play an important role in bacteria interactions with human intestinal epithelial cells. Infect Immun 2012;80(12):4089-98.

14. Stentz R, Carvalho AL, Jones EJ, Carding SR. Fantastic voyage: the journey of intestinal microbiota-derived microvesicles through the body. Biochem Soc Trans 2018;46(5):1021-27.

15. Mazzola M, Carini F, Leone A, Damiani P, Messina M, Jurjus A, Geagea Gerges A, Jurjus R, Bou Assi T, Trovato E, Rappa F, Tomasello G. Inflammatory bowel disease and colorectal cancer, nutraceutical aspects. Euromediterranean Biomed J 2016;11(17):123-29.

16. Mazzola M, Carini F, Leone A, Damiani P, Messina M, Jurjus A, Geagea Gerges A, Jurjus R, Tomasello G. Ibd, malignancy and oral microbiota: analysis of the literature. Int J Clin Dent 2016;9(9):273-78.

17. Carini F, Mazzola M, Rappa F, Jurjus A, Geagea AG, Al Kattar S, Bou-Assi T, Jurjus R, Damiani P, Leone A, Tomasello G. Colorectal Carcinogenesis: Role of Oxidative Stress and Antioxidants. Anticancer Res 2017;37(9):4759-66.

18. Carini F, Tomasello G, Jurjus A, Geagea A1, Al Kattar S, Damiani $P_{t}$ Sinagra E, Rappa F, David S, Cappello F, Mazzola M, Leone A. Colorectal cancer and inflammatory bowel diseases: effects of diet and antioxidants. J Biol Regul Homeost Agents 2017;31(3):791 95.

19. Carini F, David S, Tomasello G, Mazzola M, Damiani P, Rappa F, Battaglia L, Gerges Geagea A, Jurjus R, Leone A. Colorectal cancer: an update on the effects of lycopene on tumor progression and cell proliferation. J Biol Regul Homeost Agents 2017;31(3):769-74.

20. Woith E, Fuhrmann G, Melzig MF. Extracellular Vesicles-Connecting Kingdoms. Int J Mol Sci 2019;20(22):5695.

21. Kim JH, Lee J, Park J, Gho YS. Gram-negative and Gram-positive bacterial extracellular vesicles. Semin Cell Dev Biol 2015;40:97-104.

22. Schwechheimer C, Kuehn MJ. Outer-membrane vesicles from Gramnegative bacteria: biogenesis and functions. Nat Rev Microbiol 2015;13(10):605-19.

23. Tulkens J, De Wever O, Hendrix A. Analyzing bacterial extracellular vesicles in human body fluids by orthogonal biophysical separation and biochemical characterization. Nat Protoc 2020;15:40-67.
24. Li Z, Clarke AJ, Beveridge TJ. A major autolysin of Pseudomonas aeruginosa: subcellular distribution, potential role in cell growth and division and secretion in surface membrane vesicles. J Bacteriol 1996;178(9):2479-88.

25. Renelli M, Matias V, Lo RY, Beveridge TJ. DNA-containing membrane vesicles of Pseudomonas aeruginosa PAO1 and their genetic transformation potential. Microbiology 2004;150(Pt 7):2161-69.

26. Lee EY, Choi DS, Kim KP, Gho YS. Proteomics in gram-negative bacterial outer membrane vesicles. Mass Spectrom Rev 2008;27(6):535-55.

27. Liao S, Klein MI, Heim KP, Fan Y, Bitoun JP, Ahn SJ, Burne RA, Koo H, Brady LJ, Wen ZT. Streptococcus mutans extracellular DNA is upregulated during growth in biofilms, actively released via membrane vesicles, and influenced by components of the protein secretion machinery. J Bacteriol 2014;196(13):2355-66.

28. Fulsundar S, Harms K, Flaten GE, Johnsen PJ, Chopade BA, Nielsen KM. Gene transfer potential of outer membrane vesicles of Acinetobacter baylyi and effects of stress on vesiculation. Appl Environ Microbiol 2014;80(11):3469-83.

29. Rompikuntal PK, Thay B, Khan MK, Alanko J, Penttinen AM, Asikainen S, Wai SN, Oscarsson J. Perinuclear localization of internalized outer membrane vesicles carrying active cytolethal distending toxin from Aggregatibacter actinomycetemcomitans. Infect Immun 2012;80(1):31-42.

30. Rumbo C, Fernández-Moreira E, Merino M, Poza M, Mendez JA, Soares NC, Mosquera A, Chaves F, Bou G. Horizontal transfer of the OXA-24 carbapenemase gene via outer membrane vesicles: a new mechanism of dissemination of carbapenem resistance genes in Acinetobacter baumannii. Antimicrob Agents Chemother 2011;55(7):3084-90.

31. Ghosal A, Upadhyaya BB, Fritz JV, Heintz-Buschart A, Desai MS, Yusuf $D$, Huang D, Baumuratov A, Wang K, Galas D, Wilmes P. The extracellular RNA complement of Escherichia coli. Microbiologyopen 2015;4(2):252-66.

32. Sjöström AE, Sandblad L, Uhlin BE, Wai SN. Membrane vesicle-mediated release of bacterial RNA. Sci Rep 2015;5:15329.

33. Tsatsaronis JA, Franch-Arroyo S, Resch U, Charpentier E. Extracellular Vesicle RNA: A Universal Mediator of Microbial Communication? Trends Microbiol 2018;26(5):401-10.

34. Deatherage BL, Cookson BT. Membrane vesicle release in bacteria, eukaryotes, and archaea: a conserved yet underappreciated aspect of microbial life. Infect Immun 2012;80:1948-57.

35. Haurat MF, Elhenawy W, Feldman MF. Prokaryotic membrane vesicles: new insights on iogenesis and biological roles. Biol Chem 2015;396(2):95-109.

36. Toyofuku M, Tashiro Y, Hasegawa Y, Kurosawa M, Nomura N. Bacterial membrane vesicles, an overlooked environmental colloid: Biology, environmental perspectives and applications. Adv Colloid Interface Sci 2015;226(Pt A):65-77.

37. Manning AJ, Kuehn MJ. Contribution of bacterial outer membrane vesicles to innate bacterial defense. BMC Microbiol 2011;11:258.

38. Coleman BM, Hill AF. Extracellular vesicles - their role in the packaging and spread of misfolded proteins associated with neurodegenerative diseases. Semin Cell Dev Biol 2015;40:89-96.

39. Gho YS, Kim OY, Jang SC, Yoon CM, Kim YK. Method for treating and diagnosing cancer by using cell-derived microvesicles. Biochim Biophys Acta 2009;1788:2150-59.

40. Knox KW, Vesk M, Work E. Relation between excreted lipopolysaccharide complexes and surface structures of a lysine-limited culture of Escherichia coli. J Bacteriol 1966;92(4):1206-17.

41. Toyofuku M, Nomura N, Eberl L. Types and origins of bacterial membrane vesicles. Nat Rev Microbiol 2019;1(7):13-24.

42. Deatherage BL, Cookson BT. Membrane vesicle release in bacteria, eukaryotes, and archaea: a conserved yet underappreciated aspect of microbial life. Infect Immun 2012;80(6):1948-57.

43. Schwechheimer C, Kuehn MJ. Outer-membrane vesicles from Gramnegative bacteria: biogenesis and functions. Nat Rev Microbiol 2015; 13(10):605-19.

44. Kulp A, Kuehn MJ. Biological functions and biogenesis of secreted bacterial outer membrane vesicles. Annu Rev Microbiol 2010;64:16384.

45. Tulkens J, De Wever O, Hendrix A. Analyzing bacterial extracellular vesicles in human body fluids by orthogonal biophysical separation and biochemical characterization. Nat Protoc 2020;15:40-67.

46. Choi DS, Kim DK, Choi SJ, Lee J, Choi JP, Rho S, Park SH, Kim YK, Hwang 
D, Gho YS. Proteomic analysis of outer membrane vesicles derived from Pseudomonas aeruginosa. Proteomics 2011;11(16):3424-9.

47. Jang KS, Sweredoski MJ, Graham RL, Hess S, Clemons WM Jr. Comprehensive proteomic profiling of outer membrane vesicles from Campylobacter jejuni. J Proteomics 2014;98:90-8.

48. Haurat MF, Elhenawy W, Feldman MF. Prokaryotic membrane vesicles: new insights on biogenesis and biological roles. Biol Chem 2015;396(2):95-109. doi: 10.1515/hsz-2014-0183

49. Kim JH, Lee J, Park J, Gho YS. Gram-negative and Gram-positive bacterial extracellular vesicles. Semin Cell Dev Biol 2015;40:97-104.

50. Lee JC, Lee EJ, Lee JH, Jun SH, Choi CW, Kim SI, Kang SS, Hyun S. Klebsiella pneumoniae secretes outer membrane vesicles that induce the innate immune response. FEMS Microbiol Lett 2012;331(1):17-24.

51. Jan AT. Outer Membrane Vesicles (OMVs) of Gram-negative Bacteria: A Perspective Update. Front Microbiol 2017;8:1053.

52. Bitto NJ, Chapman R, Pidot S, Costin A, Lo C, Choi J, D'Cruze T, Reynolds EC, Dashper SG, Turnbull L, Whitchurch CB, Stinear TP, Stacey KJ, Ferrero RL. Bacterial membrane vesicles transport their DNA cargo into host cells. Sci Rep 2017;7:7072.

53. Dorward DW, Garon CF. DNA Is Packaged within Membrane-Derived Vesicles of Gram-Negative but Not Gram-Positive Bacteria. Appl Environ Microbiol 1990;56(6):1960-2.

54. Brown L, Wolf JM, Prados-Rosales R, Casadevall A. Through the wall: extracellular vesicles in Gram-positive bacteria, mycobacteria and fungi. Nat Rev Microbiol 2015;13:620-30.

55. Bitto NJ, Kaparakis-Liaskos M. The Therapeutic Benefit of Bacterial Membrane Vesicles. Int J Mol Sci 2017;18(6):1287.

56. Biagini M, Garibaldi M, Aprea S, Pezzicoli A, Doro F, Becherelli M, Taddei AR, Tani C, Tavarini S, Mora M, Teti G, D'Oro U, Nuti S, Soriani M, Margarit I, Rappuoli R, Grandi G, Norais N. The Human Pathogen Streptococcus pyogenes Releases Lipoproteins as Lipoprotein-rich Membrane Vesicles. Mol Cell Proteomics 2015;14(8):2138-49.

57. Kato $S$, Kowashi Y, Demuth DR. Outer membrane-like vesicles secreted by Actinobacillus actinomycetemcomitans are enriched in leukotoxin. Microb Pathog 2002;32(1):1-13.

58. Brown L, Wolf JM, Prados-Rosales R, Casadevall A. Through the wall: extracellular vesicles in Gram-positive bacteria, mycobacteria and fungi. Nat Rev Microbiol 2015;13(10):620-30.

59. Muralinath M, Kuehn MJ, Roland KL, Curtiss R. Immunization with Salmonella enterica serovar Typhimurium-derived outer membrane vesicles delivering the pneumococcal protein PspA confers protection against challenge with Streptococcus pneumoniae. Infect Immun 2011;79(2):887-94.

60. Petousis-Harris H, Paynter J, Morgan J, Saxton P, McArdle B, GoodyearSmith F, Black S. Effectiveness of a group B outer membrane vesicle meningococcal vaccine against gonorrhoea in New Zealand: a retrospective case-control study. Lancet 2017;390(10102):1603-610.

61. D'Souza-Schorey C, Clancy JW. Tumor-derived microvesicles: shedding light on novel microenvironment modulators and prospective cancer biomarkers. Genes Dev 2012;26(12):1287-99.

62. McDaniel K, Correa R, Zhou T, Johnson C, Francis H, Glaser S, Venter J, Alpini G, Meng F. Functional role of microvesicles in gastrointestinal malignancies. Ann Transl Med 2013;1(1):4.

63. Tomasello G, Mazzola M, Leone A, Sinagra E, Zummo G, Farina F, Damiani P, Cappello F, Gerges Geagea A, Jurjus A, Bou Assi T, Messina M, Carini F. Nutrition, oxidative stress and intestinal dysbiosis: Influence of diet on gut microbiota in inflammatory bowel diseases. Biomed Pap Med Fac Univ Palacky Olomouc Czech Repub 2016;160(4):461-66.

64. Le Doare K, Holder B, Bassett A, Pannaraj PS. Mother's Milk: A Purposeful Contribution to the Development of the Infant Microbiota and Immunity. Front Immunol 2018;9:361.

65. Garrett WS, Gallini CA, Yatsunenko T, Michaud M, DuBois A, Delaney ML, Punit S, Karlsson M, Bry L, Glickman JN, Gordon Jl, Onderdonk $\mathrm{AB}$, Glimcher LH. Enterobacteriaceae act in concert with the gut microbiota to induce spontaneous and maternally transmitted colitis. Cell Host Microbe 2010;8(3):292-300.

66. Manichanh C, Rigottier-Gois L, Bonnaud E, Gloux K, Pelletier E, Frangeul L, Nalin R, Jarrin C, Chardon P, Marteau P, Roca J, Dore J. Reduced diversity of faecal microbiota in Crohn's disease revealed by a metagenomic approach. Gut 2006;55(2):205-11.

67. Morgan XC, Tickle TL, Sokol H, Gevers D, Devaney KL, Ward DV, Reyes JA, Shah SA, LeLeiko N, Snapper SB, Bousvaros A, Korzenik J, Sands
$\mathrm{BE}$, Xavier RJ, Huttenhower C. Dysfunction of the intestinal microbiome in inflammatory bowel disease and treatment. Genome Biol 2012;13(9):R79.

68. Arthur JC, Perez-Chanona E, Mühlbauer M, Tomkovich $S$, Uronis JM, Fan TJ, Campbell BJ, Abujamel T, Dogan B, Rogers AB, Rhodes JM, Stintzi A, Simpson KW, Hansen JJ, Keku TO, Fodor AA, Jobin C. Intestinal inflammation targets cancer-inducing activity of the microbiota. Science 2012;338(6103):120-3.

69. Castellarin M, Warren RL, Freeman JD, Dreolini L, Krzywinski M, Strauss J, Barnes R, Watson P, Allen-Vercoe E, Moore RA, Holt RA. Fusobacterium nucleatum infection is prevalent in human colorectal carcinoma. Genome Res 2012;22(2):299-306.

70. McCoy AN, Araújo-Pérez F, Azcárate-Peril A, Yeh JJ, Sandler RS, Keku TO. Fusobacterium is associated with colorectal adenomas. PLoS One 2013;8(1):e53653.

71. Yáñez-Mó $M$, Siljander $P R$, Andreu $Z$, Zavec $A B$, Borràs FE, Buzas El, Buzas K, Casal E, Cappello F, Carvalho J, Colás E, Cordeiro-da Silva A, Fais S, Falcon-Perez JM, Ghobrial IM, Giebel B, Gimona M, Graner M, Gursel I, Gursel M, Heegaard NH, Hendrix A, Kierulf P, Kokubun K, Kosanovic M, Kralj-Iglic V, Krämer-Albers EM, Laitinen S, Lässer C, Lener T, Ligeti E, Linē A, Lipps G, Llorente A, Lötvall J, MančekKeber M, Marcilla A, Mittelbrunn M, Nazarenko I, Nolte-'t Hoen EN, Nyman TA, O'Driscoll L, Olivan M, Oliveira C, Pállinger É, Del Portillo HA, Reventós J, Rigau M, Rohde E, Sammar M, Sánchez-Madrid F, Santarém N, Schallmoser K, Ostenfeld MS, Stoorvogel W, Stukelj R, Van der Grein SG, Vasconcelos MH, Wauben MH, De Wever O. Biological properties of extracellular vesicles and their physiological functions. J Extracell Vesicles 2015;4:27066.

72. Mitsuhashi S, Feldbrügge L, Csizmadia E, Mitsuhashi M, Robson SC, Moss AC. Luminal Extracellular Vesicles (EVs) in Inflammatory Bowel Disease (IBD) Exhibit Proinflammatory Effects on Epithelial Cells and Macrophages. Inflamm Bowel Dis 2016;22(7):1587-95.

73. Van Niel G, Mallegol J, Bevilacqua C, Candalh C, Brugière $S$, Tomaskovic-Crook E, Heath JK, Cerf-Bensussan N, Heyman M. Intestinal epithelial exosomes carry MHC class II/peptides able to inform the immune system in mice. Gut 2003;52(12):1690-7.

74. Zhang X, Deeke SA, Ning Z, Starr AE, Butcher J, Li J, Mayne J, Cheng K, Liao B, Li L, Singleton R, Mack D, Stintzi A, Figeys D. Metaproteomics reveals associations between microbiome and intestinal extracellular vesicle proteins in pediatric inflammatory bowel disease. Nat Commun 2018;9(1):2873.

75. Ahluwalia B, Moraes L, Magnusson MK, Öhman L. Immunopathogenesis of inflammatory bowel disease and mechanisms of biological therapies. Scand J Gastroenterol 2018; 53(4):379-389

76. Rebmann V, König L, Nardi Fda S, Wagner B, Manvailer LF, Horn PA. The Potential of HLA-G-Bearing Extracellular Vesicles as a Future Element in HLA-G Immune Biology. Front Immunol 2016;7:173.

77. Reddy VS, Madala SK, Trinath J, Reddy GB. Extracellular small heat shock proteins: exosomal biogenesis and function. Cell Stress Chaperones 2018;23(3):441-54.

78. Samborski P, Grzymisławski M. The Role of HSP70 Heat Shock Proteins in the Pathogenesis and Treatment of Inflammatory Bowel Diseases. Adv Clin Exp Med 2015;24(3):525-30.

79. Cappello F, Mazzola M, Jurjus A, Zeenny MN, Jurjus R, Carini F, Leone A, Bonaventura G, Tomasello G, Bucchieri F, Conway de Macario E, Macario AJL. Hsp60 as a Novel Target in IBD Management: A Prospect. Front Pharmacol 2019;10:26.

80. Hindryckx P, Vande Casteele N, Novak G, Khanna R, D'Haens G, Sandborn WJ, Danese S, Jairath V, Feagan BG. The Expanding Therapeutic Armamentarium for Inflammatory Bowel Disease: How to Choose the Right Drug[s] for Our Patients? J Crohns Colitis 2018;12(1):105-19.

81. Bonovas S, Fiorino G, Allocca M, Lytras T, Nikolopoulos GK, PeyrinBiroulet L, Danese S. Biologic Therapies and Risk of Infection and Malignancy in Patients With Inflammatory Bowel Disease: A Systematic Review and Network Meta-analysis. Clin Gastroenterol Hepatol 2016;14(10):1385-1397.e10.

82. Deng Z, Mu J, Tseng M, Wattenberg B, Zhuang X, Egilmez NK, Wang Q, Zhang L, Norris J, Guo H, Yan J, Haribabu B, Miller D, Zhang HG. Enterobacteria-secreted particles induce production of exosomelike S1P-containing particles by intestinal epithelium to drive Th17mediated tumorigenesis. Nat Commun 2015;6:6956.

83. Chen W, Liu F, Ling Z, Tong X, Xiang C. Human intestinal lumen and mucosa-associated microbiota in patients with colorectal cancer. PloS One 2012;7(6):e39743. 
84. Ramos GP, Papadakis KA. Mechanisms of Disease: Inflammatory Bowel Diseases. Mayo Clin Proc 2019; 94(1):155-65.

85. Ahluwalia B, Moraes L, Magnusson MK, Öhman L. Immunopathogenesis of inflammatory bowel disease and mechanisms of biological therapies. Scand J Gastroenterol 2018;53(4):379-89.

86. Mima K, Nishihara R, Qian ZR, Cao Y, Sukawa Y, Nowak JA, Yang J, Dou $R$, Masugi Y, Song M, Kostic AD, Giannakis M, Bullman S, Milner DA, Baba H, Giovannucci EL, Garraway LA, Freeman GJ, Dranoff G, Garrett WS, Huttenhower C, Meyerson M, Meyerhardt JA, Chan AT, Fuchs CS, Ogino S. Fusobacterium nucleatum in colorectal carcinoma tissue and patient prognosis. Gut 2016;65:1973-80.

87. Liu W, Zhang R, Shu R, Yu J, Li H, Long H, Jin S, Li S, Hu Q, Yao F, Zhou C, Huang Q, Hu X, Chen M, Hu W, Wang Q, Fang S, Wu Q. Study of the Relationship between Microbiome and Colorectal Cancer Susceptibility Using 16SrRNA Sequencing. Biomed Res Int 2020;2020:7828392.

88. Keku TO, Dulal S, Deveaux A, Jovov B, Han X. The gastrointestinal microbiota and colorectal cancer. Am J Physiol Gastrointest Liver Physiol 2015;308(5):G351-63.

89. Sears $\mathrm{CL}$, Geis AL, Housseau F. Bacteroides fragilis subverts mucosal biology: from symbiont to colon carcinogenesis. J Clin Invest 2014;124(10):4166-72.

90. Raskov H, Burcharth J, Pommergaard HC. Linking Gut Microbiota to Colorectal Cancer. J Cancer 2017;8(17):3378-95.

91. Kim DJ, Yang J, Seo H, Lee WH, Ho Lee D, Kym S, Park YS, Kim JG, Jang IJ, Kim YK, Cho JY. Colorectal cancer diagnostic model utilizing metagenomic and metabolomic data of stool microbial extracellular vesicles. Sci Rep 2020;10(1):2860.

92. Pushalkar S, Hundeyin M, Daley D, Zambirinis CP, Kurz E, Mishra A, et al. The pancreatic cancer microbiome promotes oncogenesis by induction of innate and adaptive immune suppression. Cancer Discov 2018;8:403-16

93. Round JL, Mazmanian SK. Inducible Foxp3+ regulatory T-cell development by a commensal bacterium of the intestinal microbiota. Proc Natl Acad Sci U S A 2010;107:12204-9.
94. Popēna I, Ābols A, Saulīte L, Pleiko K, Zandberga E, Jēkabsons K, Endzelin,š E, Llorente A, Linē A, Riekstinga U. Effect of colorectal cancer-derived extracellular vesicles on the immunophenotype and cytokine secretion profile of monocytes and macrophages. Cell Commun Signal 2018;16(1):17.

95. McDaniel K, Correa R, Zhou T, Johnson C, Francis H, Glaser S, Venter J, Alpini G, Meng F. Functional role of microvesicles in gastrointestinal malignancies. Ann Transl Med 2013;1(1):4.

96. Mitsuhashi S, Feldbrügge L, Csizmadia E, Mitsuhashi M, Robson SC, Moss AC. Luminal Extracellular Vesicles (EVs) in Inflammatory Bowel Disease (IBD) Exhibit Proinflammatory Effects on Epithelial Cells and Macrophages. Inflamm Bowel Dis 2016;22(7):1587-95.

97. Voudoukis E, Vetsika EK, Giannakopoulou K, Karmiris K, Theodoropoulou A, Sfiridaki A, Georgoulias V, Paspatis GA, Koutroubakis IE. Distinct features of circulating microparticles and their relationship with disease activity in inflammatory bowel disease. Ann Gastroenterol 2016;29(2):180-7.

98. Valter M, Verstockt S, Finalet Ferreiro JA, Cleynen I. Extracellular vesicles in inflammatory bowel disease: small particles, big players. J Crohns Colitis 2021;15(3):499-510.

99. Yau TO, Wu CW, Tang CM, Chen Y, Fang J, Dong Y, Liang Q, Ng SS, Chan FK, Sung JJ, Yu J. MicroRNA-20a in human faeces as a non-invasive biomarker for colorectal cancer. Oncotarget 2016;7(2):155968.

100. Cecil JD, O'Brien-Simpson NM, Lenzo JC, Holden JA, Singleton W, Perez-Gonzalez A, Mansell A, Reynolds EC. Outer Membrane Vesicles Prime and Activate Macrophage Inflammasomes and Cytokine Secretion In Vitro and In Vivo. Front Immunol 2017;8:1017.

101. Davitt C.J.H., Petersen H.E., Kikendall N.L., Lavelle E.C., Morici L.A. Naturally-derived bacterial nano-particles engage diverse innate receptors, driving the activation of dendritic cells and leading to the establishment of potent adaptive immune responses. J. Immunol 2016;196:76.

102. Ogata-Kawata H, Izumiya M, Kurioka D, Honma Y, Yamada Y, Furuta K, Gunji T, Ohta H, Okamoto H, Sonoda H, Watanabe M, Nakagama $\mathrm{H}$, Yokota J, Kohno T, Tsuchiya N. Circulating exosomal microRNAs as biomarkers of colon cancer. PLoS One 2014;9(4):e92921. 